\title{
Hipergranulación en heridas crónicas: un problema ocasional pero no infrecuente
}

\section{Hypergranulation of chronic wounds: an occasional but not infrequent problem}

Daniel Chaverri Fierro

\author{
Correspondencia: \\ Daniel Chaverri Fierro \\ C/ Cabestany 6, 60 $2^{\circ}$ \\ 22005-Huesca \\ Tfno.: 605392395 \\ E-mail: danichaverri@hotmail.com
}

Enfermero. Unidad de Geriatría, Hospital Sagrado Corazón (Huesca). Diplomado en Enfermería. Licenciado en Antropología, Experto GNEAUPP nivel avanzado. Máster en Cuidados y Curas de Heridas Crónicas. Posgrado en Enfermería Quirúrgica.

\section{RESUMEN}

La hipergranulación es un problema ocasional, pero a la vez no infrecuente, con el que se enfrentan muchos clínicos responsables del tratamiento de heridas en su práctica diaria. Este fenómeno ocurre en un amplio abanico de heridas que incluyen las incisiones y heridas posquirúrgicas, los estomas (gastrostomías, traqueostomías, etc.) y las heridas crónicas.

El objetivo del presente artículo es cuantificar y analizar la evidencia generada en torno al tema de la hipergranulación en las heridas crónicas, mediante la búsqueda bibliográfica en diversas bases de datos.

Tras el análisis y revisión de los diferentes documentos recuperados se evidencia, tanto cuantitativa como cualitativamente hablando, una escasez importante de investigación en torno a la hipergranulación en heridas crónicas. Esto hace que el problema no se halle lo suficientemente explicado y que no existan evidencias sólidas que justifiquen el uso de un tratamiento sobre otro.

\section{PALABRAS CLAVE}

Hipergranulación, herida crónica, revisión.

\section{SUMMARY}

Hypergranulation is an occasional but no infrequent problem, which many clinicians face in their daily practice.

This phenomenon occurs in a variety of wounds that includes post-surgical incisions and wounds, stomas (gastrostomies, tracheotomies...) and chronic wounds. The objective of the present article is to quantify and to analyze the evidence generated around the topic of the hypergranulation in chronic wounds, through the bibliographical search in diverse data bases.

After the analysis and revision of the different recovered documents it is demonstrated, both in terms of quantity and quality, an important shortage of investigation around

\section{INTRODUCCIÓN}

La hipergranulación es un problema ocasional, pero a la vez no infrecuente, con el que se enfrentan muchos clínicos responsables del tratamiento de heridas en su práctica diaria. Este fenómeno ocurre en un amplio abanico de heridas que incluyen las incisiones y heridas posquirúrgicas, los estomas (gastrostomías, traqueostomías, etc.) y las heridas crónicas.

El término hipergranulación describiría el crecimiento exuberante y desmesurado del tejido de granulación durante la fase proliferativa del proceso de cicatrización. Un crecimiento anómalo que rebasaría los bordes de la herida y que impediría por tanto la correcta epitelización y entrada de la lesión en la fase de maduración (Fig. 1).

El objetivo que nos planteamos en este trabajo fue cuantificar y analizar la evidencia generada en torno al tema de la hipergranulación en las heridas crónicas, para profundizar así en el conocimiento de dicho fenómeno mediante la búsqueda bibliográfica en diversas bases de datos.

El presente artículo surge como consecuencia de la revisión bibliográfica lle- 
the hypergranulation in chronic wounds. Therefore, the problem is not sufficiently explained and solid evidences do not exist to justify the use of a treatment over another one.

\section{KEY WORDS}

Hypergranulation, chronic wound, review.

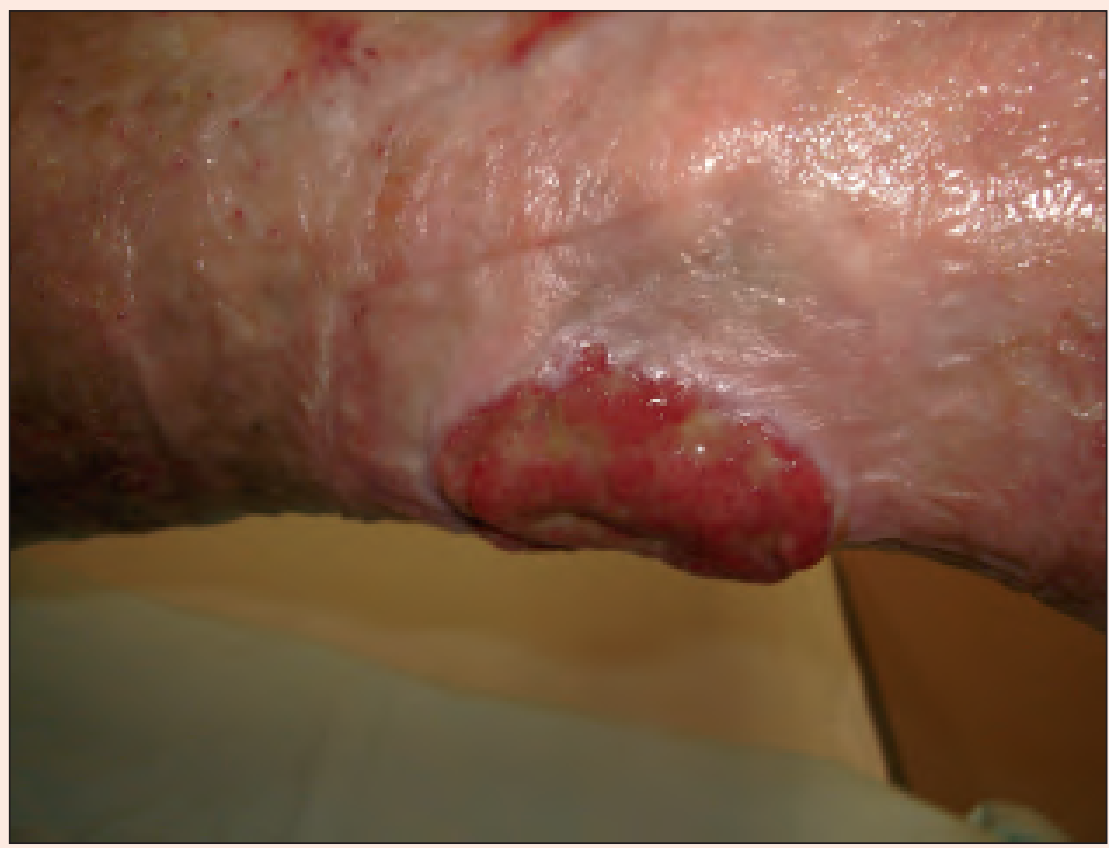

Fig. 1. Detalle de una herida con tejido de hipergranulación.

vada a cabo para un estudio en el que estamos trabajando actualmente, que pretende generar evidencias en torno a una opción terapéutica concreta para el tratamiento de la hipergranulación.

\section{METODOLOGÍA}

Se realizó una búsqueda bibliográfica durante los meses de febrero y marzo de 2007 en las siguientes bases de datos: MEDLINE, EMBASE, ProQuest, COCHRANE y CUIDEN. Se planteó únicamente limitar la búsqueda a estudios en humanos en las bases de datos MEDLINE y EMBASE para hacer la búsqueda más específica.

La variabilidad del lenguaje científico hace que podamos encontrarnos con varios términos que describan un mismo concepto. Así, además de la traducción literal del término hipergranulación: hypergranulation, sinónimos del mismo como overgranulation, exuberant granulation o proud flesh fueron utilizados en las diferentes estrategias de búsqueda. nuestra búsqueda se procedió a seleccionar los artículos que versaran específicabúsqueda en cita y resumen utilizando la palabra clave hypergranulation $\mathrm{o}$ sinónimos, para después cruzarlas con los términos ulcer y wound.

En el caso de la base de datos ProQuest se planteo la búsqueda en cita y texto para conseguir más sensibilidad y recuperar un mayor número de artículos.

*En cita y resumen. mente sobre hipergranulación en heridas crónicas, para posteriormente pasar a revisarlos y analizarlos en profundidad.

\section{RESULTADOS}

Las Tablas 1, 2 y 3 muestran los resultados numéricos de las diferentes estrategias de búsqueda llevadas a cabo en las bases MEDLINE, EMBASE y ProQuest. Cabe destacar que los términos hypergranulation (o sinónimos) no se hallan indexados en el MesH. En las bases de datos COCHRANE y CUIDEN no se consiguió recuperar ningún artículo.

De todos los documentos recuperados se eliminaron aquellos que se encontraban por duplicado, quedando 16 artículos para su análisis exhaustivo, de donde se extrajo la información más relevante para realizar la síntesis que se expone en el siguiente apartado.

\section{DISCUSIÓN Y ANÁLISIS}

A pesar de ser un problema citado con relativa frecuencia en diversa literatura, la extensión y dimensión del mismo permanece todavía sin esclarecer, ya que son pocos los artículos y referencias bibliográficas que versen sobre el mismo. Según Nelson (1) habría dos factores clave que explicarían la escasez de trabajos de investigación en esta materia, así como la ausencia de evidencias sólidas. Por una parte, el hecho de que la hipergranulación no cause molestias ni suponga un riesgo inmediato para el bienestar del paciente hace que no se vea como un problema que requiera investigación urgente. Por otra, la dificultad para obtener una muestra de sujetos con un tamaño suficiente para dar potencia al estudio.

Una vez obtenidos los resultados de

\section{Tabla 1. Estrategias de búsqueda llevadas a cabo en la base} de datos MEDLINE

\begin{tabular}{|l|c|c|c|c|}
\hline Términos* & Total & Humanos & AND ulcer & AND wound \\
\hline Exuberant granulation & 61 & 30 & $(6) 3^{* *}$ & $(14) 4^{* *}$ \\
Hypergranulation & 44 & 28 & $5^{* *}$ & $(16) 14^{* *}$ \\
Overgranulation & 6 & 4 & 0 & $4^{* *}$ \\
Proud flesh & 5 & 4 & 0 & 0 \\
\hline
\end{tabular}

**Artículos que versan específicamente sobre heridas crónicas. 
Tabla 2. Estrategias de búsqueda llevadas a cabo en la base de datos PROQUEST (Health \& Medical Complete, ProQuest Nursing \& Allied Health Source)

\begin{tabular}{|l|c|c|c|c|}
\hline Términos & Cita y resumen & Cita y texto & AND ulcer & AND wound \\
\hline Exuberant granulation & 9 & 61 & $(8) 4^{*}$ & $(22) 5^{*}$ \\
Hypergranulation & 0 & 16 & $3^{*}$ & $(20) 11^{*}$ \\
Overgranulation & 0 & 16 & $4^{*}$ & $7^{*}$ \\
Proud flesh & 0 & 7 & $2^{*}$ & $(4) 2^{*}$ \\
\hline
\end{tabular}

*Artículos que versan específicamente sobre heridas crónicas.

Tabla 3. Estrategias de búsqueda llevadas a cabo en la base de datos EMBASE

\begin{tabular}{|l|c|c|}
\hline Términos & $\begin{array}{c}\text { Cita y Resumen } \\
\text { (en humanos. no. + límites) }\end{array}$ & AND ulcer \\
\hline Exuberant granulation & 33 & 10 \\
Hypergranulation & 29 & 6 \\
Overgranulation & 5 & 0 \\
Proud flesh & 4 & 0 \\
\hline
\end{tabular}

\section{Fisiopatología}

de la hipergranulación

El mecanismo fisiopatológico de la hipergranulación no está del todo claro ni definido hoy día. Parece deberse a una excesiva y prolongada respuesta inflamatoria, que sería la responsable última de la proliferación desmesurada y anómala del tejido de granulación.

Los agentes causantes de esta respuesta inflamatoria serían varios según la información aportada por la diversa literatura revisada. Algunos autores apuntan como agente causal la presencia de cuerpos extraños: suturas, fibras de celulosa, restos de gasas, sondas de gastrostomía, cánulas de traqueostomía o catéteres suprapúbicos. En el caso de estos tres últimos, la fricción constante de la sonda o catéter con el punto de inserción provocaría la respuesta inflamatoria prolongada $(1,2)$. Sin embargo, es frecuente la aparición de hipergranulomas sin la presencia de estos cuerpos extraños, como es el caso de las heridas crónicas.

Otros autores muestran evidencias in vitro de que el uso de apósitos oclusivos (hidrocoloides) puede originar la aparición del problema en cuestión. Estas conclusiones in vitro no llegaron nunca a confirmarse in vivo (3).
El exceso de humedad en el lecho lesional podría ser otro de los causantes de la hipergranulación. Una correcta gestión del exudado y un manejo adecuado de las herramientas encaminadas a aportar humedad (hidrogeles) evitarían su aparición (4-6).

Donde parece existir un mayor consenso es en la hipótesis de la infección o elevada carga bacteriana como agente desencadenante de la hipergranulación. La infiltración de bacterias en lecho lesional provocaría una respuesta inflamatoria descontrolada, dando lugar al hipergranuloma $(2-4,7)$. Así, Stone sugiere que en determinados sujetos, microorganismos como Staphylococcus y Streptococcus podrían ser los responsables de que los leucocitos polimorfonucleares tuvieran una respuesta inflamatoria excesiva y continuada, liberando una serie de péptidos que estimularían sobremanera la proliferación fibroblástica y la formación de matriz extracelular (8).

Es importante destacar que la malignización en una úlcera puede adoptar una apariencia similar a la del tejido de hipergranulación. El riesgo de malignización es proporcional a la cronificación en el tiempo de la úlcera y afecta principalmente a las ulceras venosas (9). La malignización de una úl- cera crónica es conocida bajo el término de úlcera de Marjolin, siendo el carcinoma celular escamoso el responsable más frecuente de la misma. La aparición de signos como hipergranulación y sangrado del lecho lesional en heridas de larga evolución con escasa o nula tendencia a la cicatrización, debería alertarnos sobre la posibilidad de una malignización en la misma, haciéndose necesaria una biopsia de los tejidos para descartar esta situación (9-11).

\section{Opciones terapéuticas}

Consecuencia de la existencia de varias hipótesis explicativas para el fenómeno de la hipergranulación; el abordaje y manejo de la misma tampoco está del todo claro y no existen evidencias sólidas que justifiquen la elección de un tratamiento sobre otro.

Lo que sí podemos concluir del análisis de la bibliografía consultada es que en líneas generales el manejo de la hipergranulación se basaría en dos pilares básicos:

a) Disminución de la respuesta inflamatoria para conseguir la reducción del hipergranuloma.

b) La eliminación de la posible etiología que causa el hipergranuloma (infección o elevada carga bacteriana, exceso de humedad, presencia de un cuerpo extraño, fricción de sonda estomal).

\section{Disminución de la respuesta inflamatoria}

Existen varios autores que defienden la retirada del tejido granulomatoso mediante sustancias cáusticas como sería el nitrato de plata (barritas de nitrato de plata) (7). Esta sustancia destruiría el exceso de fibroblastos y matriz extracelular eliminando, por tanto, el hipergranuloma de una forma traumática. Sin embargo, esta opción terapéutica ha sido y es muy discutida, ya que este procedimiento, además de generar dolor y molestias en el paciente, genera un trauma en el lecho lesional que lleva a la herida a su fase inflamatoria, iniciándose de nuevo el proceso de cicatrización y retrasando por tanto el cierre de la misma. Otros inconvenientes como la argiria son mencionados por 
los detractores de este procedimiento $(3,12)$. Alternativas traumáticas como el uso de sustancias cáusticas o la exéresis del tejido de hipergranulación estarían justificadas según Zitelli (2) únicamente cuando el hipergranuloma es pedunculado y se extiende por encima de los bordes de la herida (Fig. 2).

Existen diversos autores que apuestan por una vía más conservadora y menos traumática recomendando el uso de corticoides tópicos como herramienta para amortiguar la respuesta inflamatoria, y por lo tanto disminuir la hipergranulación. Los corticoides, además de frenar la respuesta inflamatoria, presentan efectos antimitóticos para fibroblastos y queratinocitos y ralentizan de manera importante la síntesis de los componentes de la matriz extracelular (13). Se aconseja su aplicación durante períodos cortos de tiempo debido a que su uso terapéutico prolongado podría alterar y retrasar la cicatrización por los efectos antes señalados (12) (Fig. 3).

Lain muestra en un estudio de caso el tratamiento de un hipergranuloma en una úlcera de pie diabético plantar utilizando Imiquimod; sustancia ésta utilizada por dermatólogos en el tratamiento de neoplasias ricas en vasos sanguíneos como los hemangio-

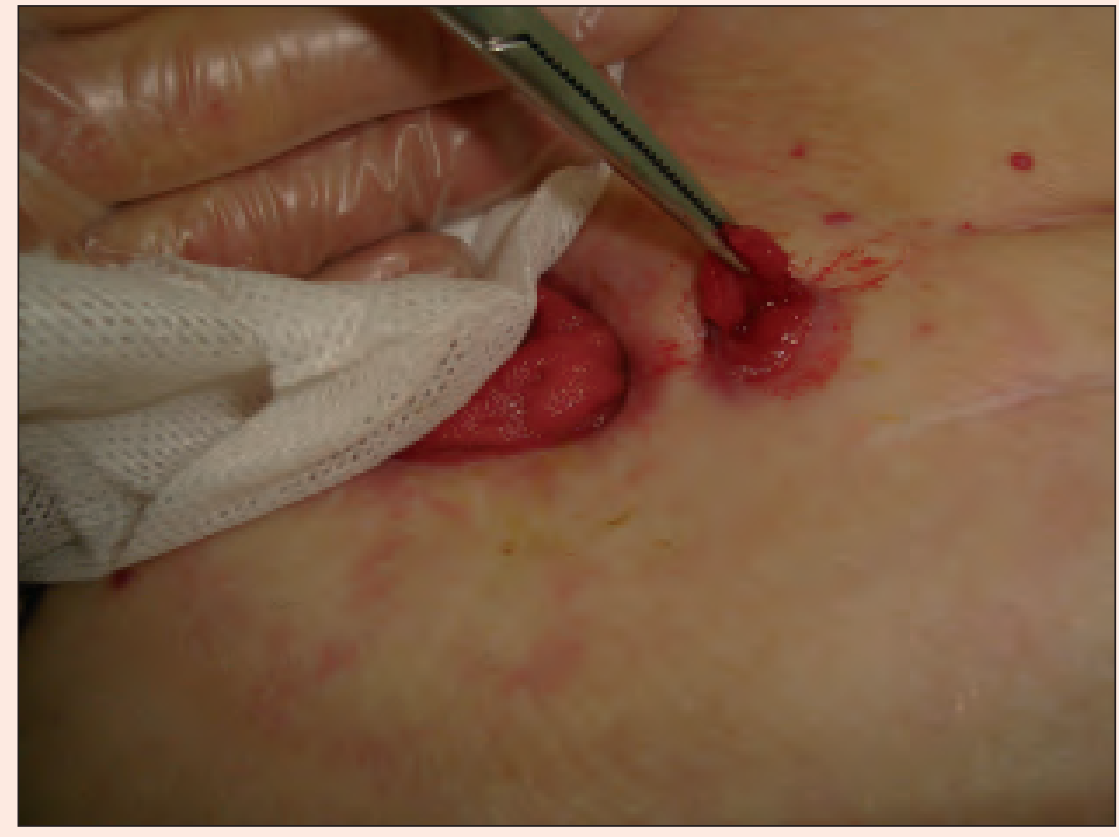

Fig. 2. Hipergranuloma pedunculado en una dehiscencia quirúrgica próxima a un estoma de colostomía.

mas. Lain extrapola el uso de Imiquimod a un hipergranuloma valiéndose de sus propiedades antiangiogénicas para conseguir la reducción de la proliferación de fibroblastos y, por tanto, de la situación de hipergranulación (14). Esta última opción terapéutica es tan novedosa como infrecuente.

La aplicación de una ligera presión sobre el lecho lesional, por mediación

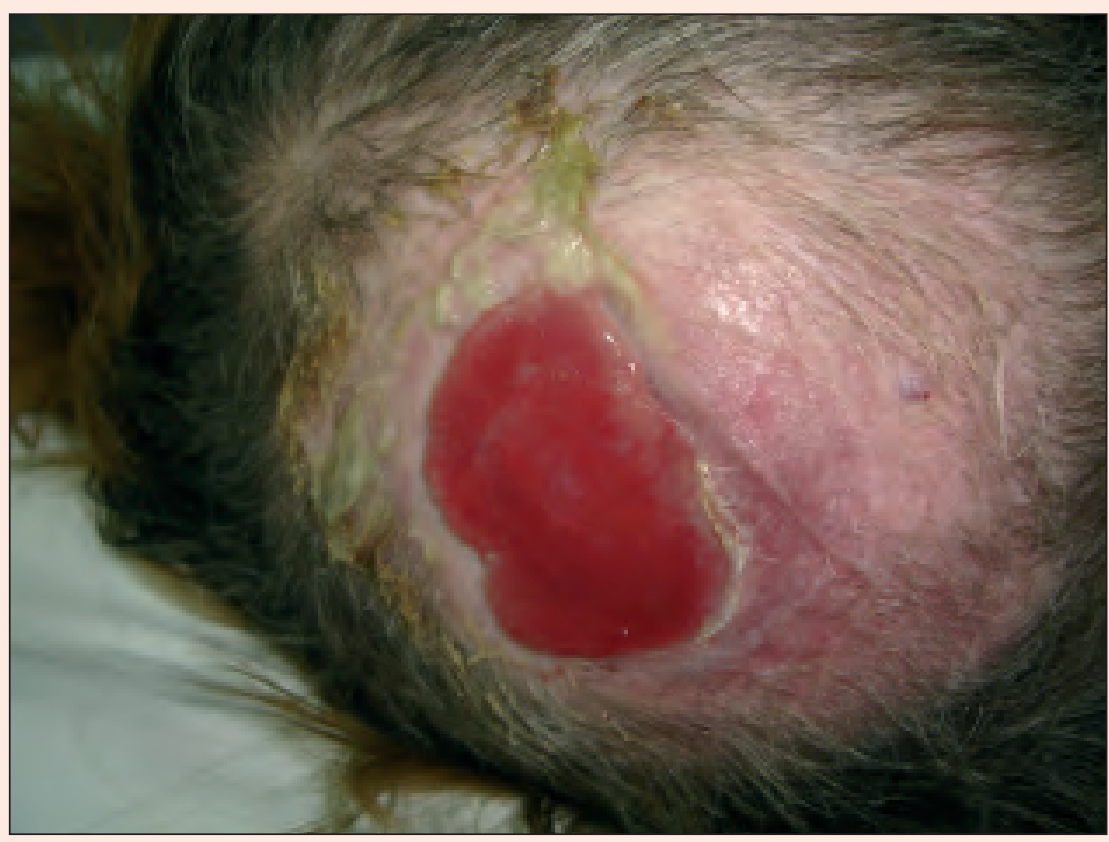

Fig. 3. Úlcera por presión occipital con tejido de hipergranulación que rebosa y se extiende por encima de los bordes de la herida. de un apósito secundario acolchado, puede ser beneficiosa según Young (12) para reducir la hipergranulación, si bien no existen evidencias que respalden esta práctica.

La terapia con láser, así como la crioterapia, son también opciones terapéuticas mencionadas en la literatura.

\section{Control etiológico}

En todos los casos anteriores, la mayoría de los autores apuestan por un control etiológico de los supuestos elementos que causan la hipergranulación, entre ellos la infección o elevada carga bacteriana. Por ello, aconsejan combinar las opciones terapeúticas antes señaladas con antibióticos tópicos, o incluso con apósitos antimicrobianos que contienen plata.

Así, por ejemplo, Lain, en su caso clínico, asocia un antibiótico tópico (mupirocina) al tratamiento con Imiquimod (14). Hawkins-Bradley utiliza el nitrato de plata como elemento para la eliminación del granuloma asociando a esta terapia un apósito de alginato cálcico con plata nanocristalina (Acticoat Absorbent Dressing ${ }^{\circledR}$, Smith $\&$ Nephew) para controlar la carga bacteriana y las posibles recidivas del hipergranuloma (7). Leak presenta una serie de casos que muestran el cuidado del lugar de inserción de gastros- 
tomías endoscópicas percutáneas, observando una disminución de las infecciones y reducción de las hipergranulaciones utilizando un apósito de carbón activo y plata (Actisorb Silver $220^{\circledast}$, Johnson \& Johnson) (15).

Otros estudios, como el de Harris y Rolstad, muestran cómo el correcto control del exudado reduce la hipergranulación en $2 \mathrm{~mm}$ en una serie de 12 heridas durante dos semanas de tratamiento con un apósito de espuma de poliuretano $\left(\right.$ Lyofoam $\left.^{\circledR}\right)$ (2). En la misma línea, Fraser indica cómo en algunos casos la correcta gestión del exudado con un apósito de alginato cálcico $\left(\right.$ Sorbsan $\left.^{\circledR}\right)$ puede reducir las hipergranulaciones en heridas de pie diabético (5).
En el caso de las incisiones de tubos de gastrostomía, una incorrecta fijación de los mismos puede provocar hipergranulación debido al estrés mecánico generado por la fricción y la posible salida al exterior de contenido gástrico. Por ello, en estos casos una correcta fijación del tubo disminuirá la frecuencia de aparición de hipergranulomas (4).

\section{CONCLUSIONES}

La escasez de investigación en torno a la hipergranulación hace que este problema no se halle lo suficientemente explicado y que no existan evidencias sólidas que justifiquen el uso de un tratamiento sobre otro. Hasta el momento las opciones terapéuticas se basan en opiniones de expertos, estudios de caso y estudios de series de casos con una baja potencia muestral.

A falta de mayor investigación que profundice en la fisiopatología y el tratamiento de la hipergranulación, y tras el análisis de la diferente literatura, la recomendación que podemos dar a la hora de seleccionar la mejor opción terapéutica entre las diferentes posibles se fundamentaría en la elección del método menos traumático posible en función del tipo de hipergranuloma, reservando las opciones más traumáticas para los casos de mayor gravedad y dimensión.

\section{BIBLIOGRAFÍA}

1. Nelson L. Wound care. Points of friction. Nurs Times 1999; 95 (34): 72-3.

2. Harris A, Rolstad BS. Hypergranulation tissue: a nontraumatic method of management. Ostomy Wound Manage 1994; 40 (5): 20-2, 24, 2630 .

3. Dunford C. Hypergranulation tissue J Wound Care 1999; 8 (10): 5067.

4. Rollins H. Hypergranulation tissue at gastrostomy sites. J Wound Care 2000; 9 (3): 127-9.

5 . Fraser R. Sorbsan calcium alginate fibre dressings in footcare. Biomaterials $1983 ; 4$ (3): 222-4.

6. Dovison R. Wound healing and infection in nail matrix phenolization wounds. Does topical medication make a difference? J Am Podiatr Med Assoc 2001; 91 (5): 230-3.

7. Hawkins-Bradley B, Walden M. Treatment of a nonhealing wound with hypergranulation tissue and rolled edges. J Wound Ostomy Continence Nurs 2002; 29 (6): 320-4.
8. Stone OJ. Hyperinflammatory proliferative (Blastomycosis-like) pyodermas: Rewiew, mechanisms, and therapy. Journal Dermatologic Surgery and Oncology 1986; 12 (3): 271-3.

9. Mseddi M, Turki H, Bouassida S, Marrekchi S, Meziou TJ, Boudaya S et al. Malignant change in leg ulcer: 8 cases studies. Révue de Gériatrie 2005; 30 (7): 471-4.

10. Walsh R. Improving diagnosis of malignant leg ulcers in the community. Brit J Nurs 2002; 11 (9): 604-13.

11. Eltorai M, Montroy RE, Kobayashi M, Jakowathz J, Gutiérrez P. Marjolin's ulcer in patients with spinal cord injury. J Spinal Cord Med 2002; 25 (3): 191-6.

12. Young T. Common problems in wound care: overgranulation. Brit J Nurs 1995; 4 (3): 169-70.

13. Dougthy DB, Sparks-Defriese B. Wound-healing physiology. In: Bryant RA, Nix DP. Acute and Chronic Wounds ( $3^{\text {th }}$ ed.). St Louis: Mosby Elsevier, 2007; 56-81.

14. Lain EL, Carrington PR. Imiquimod treatment of exuberant granulation tissue in a nonhealing diabetic ulcer. Arch Dermatol 2005; 141 (11): 1368-70.

15. Leak K. PEG site infections: a novel use for Actisorb Silver 220. Br J Community Nurs 2002; 7 (6): 321-5. 